\title{
Vögel im Palmengarten
}
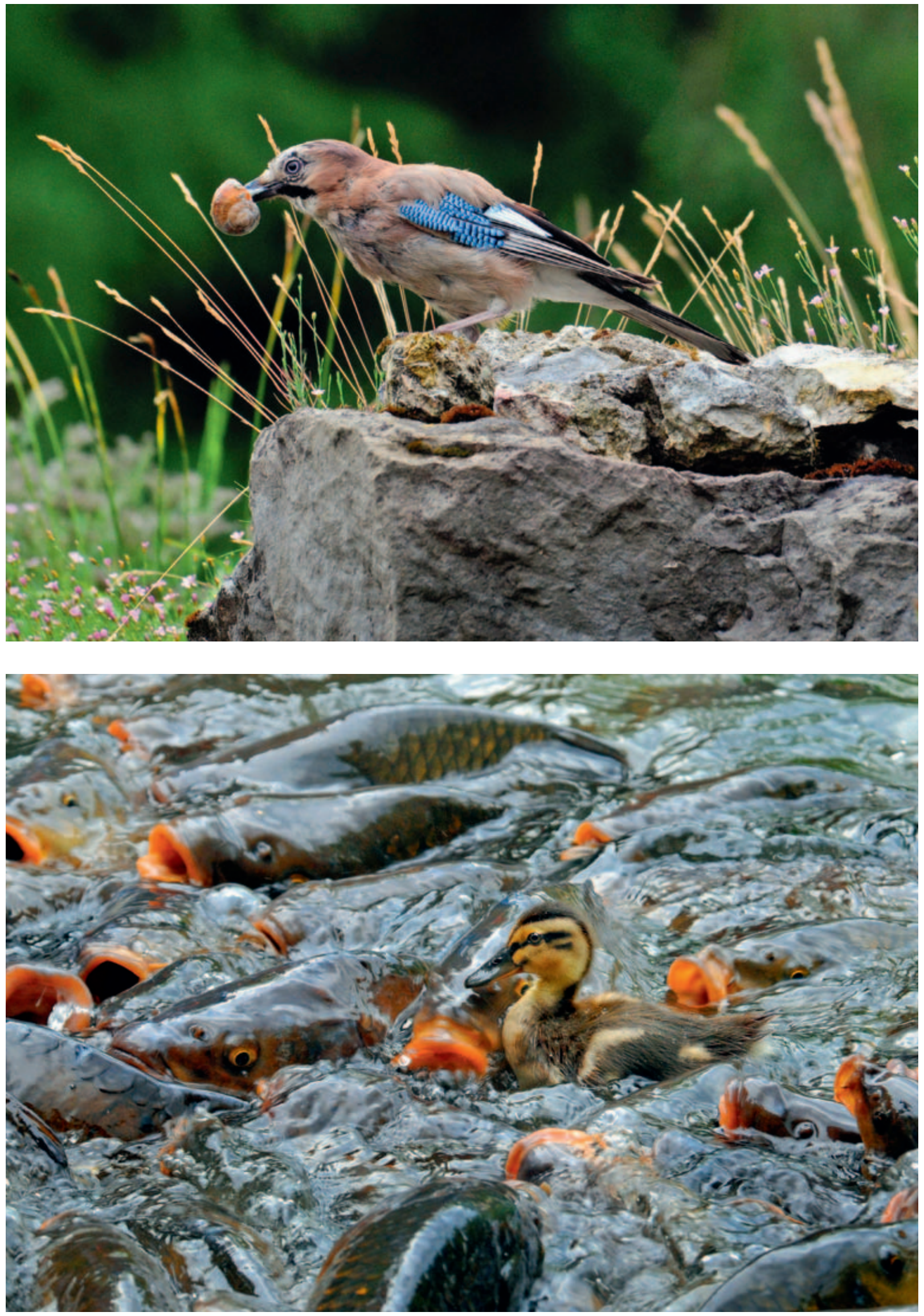

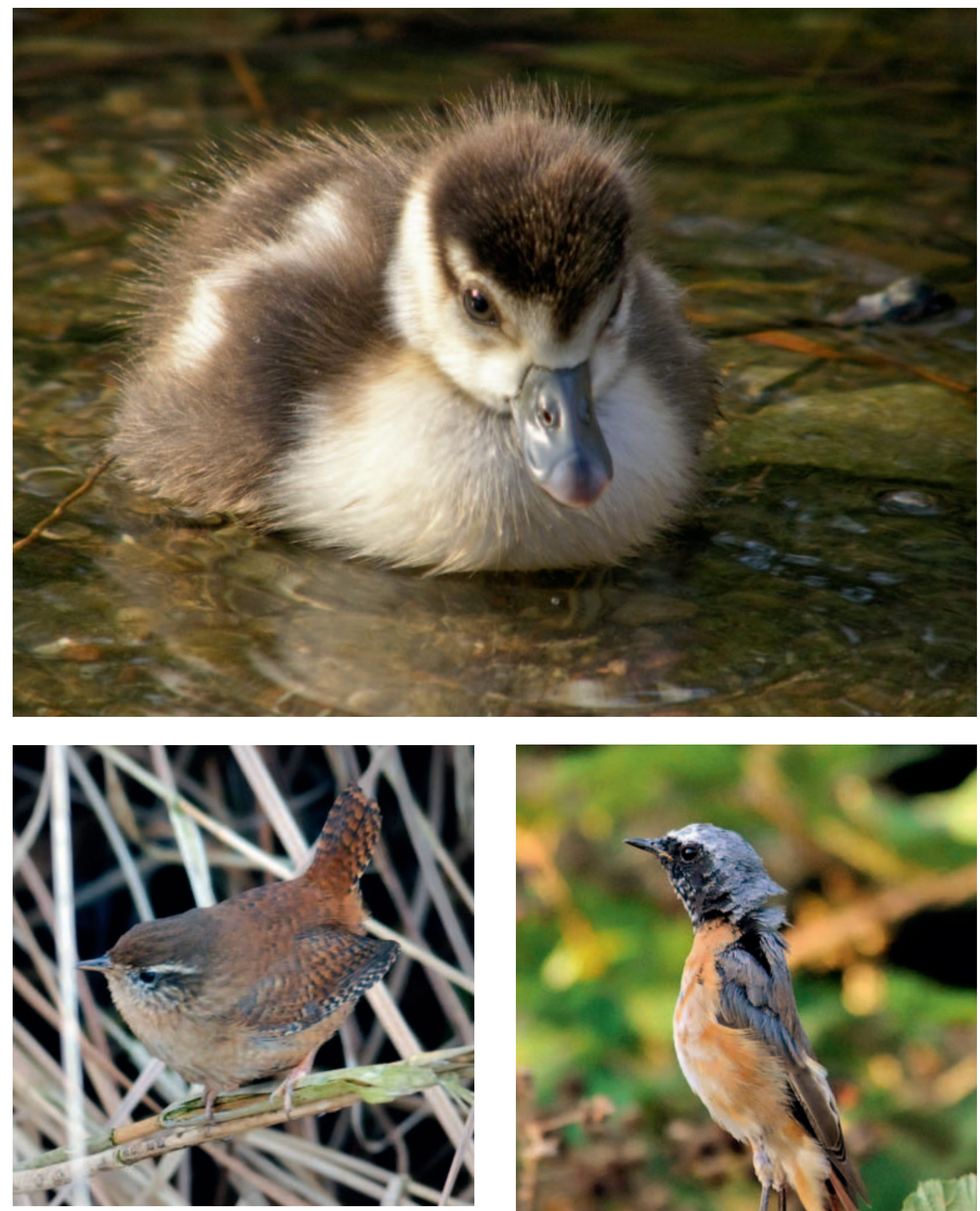

Abb. 1 (S. 162, oben): Eichelhäher im Steingarten.

Abb. 2 (S. 162, unten): Stockentlein im Karpfenweiher. Abb. 3 (oben): Junge Nilgans.

Abb. 4 (unten rechts): Gartenrotschwanz.

Abb. 5 (unten links): Zaunkönig.

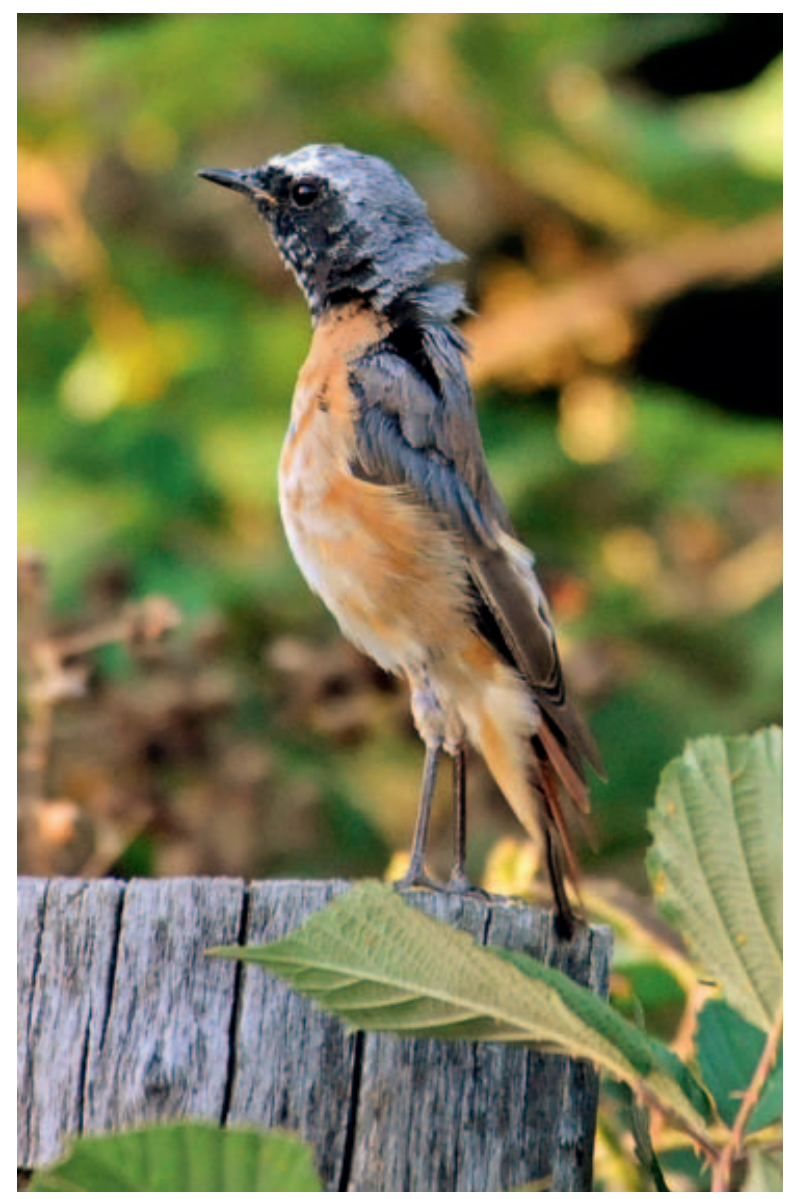

